\title{
Article \\ Stability Analysis of Shunt Active Power Filter with Predictive Closed-Loop Control of Supply Current
}

\author{
Agata Bielecka ${ }^{1, *(D)}$ and Daniel Wojciechowski ${ }^{2}$ (D) \\ 1 Department of Ship Automation, Faculty of Electrical Engineering, Gdynia Maritime University, \\ 81-225 Gdynia, Poland \\ 2 Department of Power Electronics and Electrical Machines, Faculty of Electrical and Control Engineering, \\ Gdansk University of Technology, 80-233 Gdańsk, Poland; daniel.wojciechowski@pg.edu.pl \\ * Correspondence: a.bielecka@we.umg.edu.pl
}

Citation: Bielecka, A.;

Wojciechowski, D. Stability Analysis of Shunt Active Power Filter with Predictive Closed-Loop Control of Supply Current. Energies 2021, 14, 2208. https://doi.org/10.3390/en14 082208

Academic Editors: Marcin Maciążek and Mihaela Popescu

Received: 16 March 2021

Accepted: 12 April 2021

Published: 15 April 2021

Publisher's Note: MDPI stays neutral with regard to jurisdictional claims in published maps and institutional affiliations.

Copyright: (c) 2021 by the authors. Licensee MDPI, Basel, Switzerland. This article is an open access article distributed under the terms and conditions of the Creative Commons Attribution (CC BY) license (https:// creativecommons.org/licenses/by/ $4.0 /)$.

\begin{abstract}
This paper presents a shunt active power filter connected to the grid via an $L C L$ coupling circuit with implemented closed-loop control. The proposed control system allows selective harmonic currents compensation up to the 50th harmonic with the utilization of a model-based predictive current controller. As the system is fully predictive, it provides high effectiveness of the harmonic reduction, which is proved by waveforms achieved in performed tests. On the other hand, the control system is prone to loss of stability. Therefore, the paper is focused on the stability analysis of the discussed control system with the additional outer control loop of the supply current with predictive control of this current. The conducted stability analysis encompasses the assessment of system stability as a function of the coupling circuit parameter identification accuracy, whose values are implemented in the current controller, as well as parameters such as the sampling frequency and proportional-integral (PI) controller coefficients. The obtained results show that the ranges of the $L C L$ circuit parameter identification accuracy for which the system remains stable are relatively wide. However, the most effective compensation of the supply current distortion is achieved for the parameters identified correctly, and the greatest impact on the compensation quality has the value of $L_{1}$ inductance.
\end{abstract}

Keywords: shunt active power filter; harmonic currents compensation; closed-loop control; stability analysis; predictive control

\section{Introduction}

The active power filter (APF) is a proven tool for power quality problems as it provides controllable and very effective harmonic currents compensation. On account of this, such a device has become more and more popular, which is reflected by the numerous research works on its control strategies published in scientific journals.

APFs can be classified into three types on the basis of their topology and connection to the power grid. The series APF, which is connected to the grid via a coupling transformer, constitutes a controlled voltage source and is utilized to directly mitigate voltage distortion [1,2]. However, the shunt APF, being connected in parallel between the supply and non-linear loads via a passive circuit, compensates directly for current distortion [3-30] and also, indirectly, the grid voltage. It acts as a controlled current source and is characterized by more merits in comparison to the series APF, which has made it widely used in industrial applications. The hybrid APF [31,32], holding the advantages of both passive and active power filters, combines improved performance and cost-effective solutions. There are two prominent configurations of the hybrid APF: a combination of the series APF and a shunt passive filter and a combination of the shunt APF and a shunt passive filter.

There are two main control strategies for the shunt APF in accordance with the control theory: feedforward open-loop control [8,11,17,19,24-26] and feedback closed-loop 
control $[3-7,9-12,15,16,18,21-23,30]$. They are based on the selection of the current around the point of common coupling (PCC), which is used in the control. The load current measurement is used to determine the set current in the open-loop system, while the supply current measurement is utilized in the closed-loop control. This control system is more complex than open-loop control as it requires the use of an outer control loop of the upstream current with simultaneous control of this current. It is less popular than the open-loop control structure on account of the fact that it is more prone to loss of stability. On the other hand, it ensures a higher level of harmonic currents compensation. Another less common control strategy is based on the measurement of voltage in the PCC. The reference current, which is proportional to voltage harmonic components, ensures compensation of distortions regardless of whether they come from the load or the supply side [28,29].

Determination of current harmonics to be compensated is significant and established on their detection with the utilization of the particular techniques in either the time or the frequency domain. The former approach encompasses methods such as instantaneous reactive power theory ( $p-q$ theory) $[8,13-15]$, stationary reference frame theory [12] or synchronous rotational reference frame theory relying on Park's transformation (d-q transformation) $[3,7,18,22,25]$, whereas the latter comprises Fourier transform techniques (FFT, DFT) $[11,20]$ as well as their variations [4-7,11]. Apart from this, harmonic currents compensation can be broadband or selective, often comprising harmonic current orders equal to $6 k \pm 1$ as they are the most common existing in three-phase plants. There are also new approaches for this issue, such as the one presented in [32], which shows a hybrid APF defining the reference current on the basis of the sliding mode control. Another interesting study case is presented in [18], which proposes rectifying the problem in the electromagnetic compatibility of power electronics equipment by developing the APF's high control accuracy based on d-q control.

A crucial element of the APF control structure is a current controller due to the fact that it determines the quality of the reference current tracking. There is a wide range of various current controllers, among which one can distinguish a simple proportional-integral (PI) controller $[3,4,7,10,15,17,18]$, a proportional-resonance (PR) controller [13,16,23], a deadbeat controller [12] and a model-based predictive controller (MPC) $[8,20]$. The challenges for current controllers include maximizing the harmonic currents compensation, correction of delays between the measurements and control and cooperation with the coupling circuit. In APFs, an $L C L$ circuit has to be used as a coupling circuit due to its facility to mitigate current ripples resulting from the pulse modulation of the converter. However, it causes a resonance hazard. One solution to this issue is applying the active damping method $[16,23,33]$. The literature [16] presents the combination of using a current controller based on PR units with phase compensation along with the inverter-side current feedback active damping to attenuate the $L C L$ resonance peak. Another approach for developing a current controller is shown in [22], which presents a current controller consisting of $n$ parallel-connected PI controllers. There is a coupling circuit in the form of the inductance which does not cause a risk of resonance, but it is less effective in attenuating the switching ripples. However, although the mentioned solutions are well developed, they do not compensate the delays resulting from the discrete control system. Achieving this is possible with the utilization of a predictive current controller. The MPC of the control system proposed in this paper not only compensates for the mentioned delays but also fully blocks the resonance of the $L C L$ circuit and is characterized by great dynamics of operation. Using this controller with the additional outer control loop of the upstream current in a control system of an APF is a novelty. Nevertheless, the application of the additional outer control loop for the upstream current with the predictive control of this current implies the necessity of applying prediction also when determining the reference current, which makes it more complex. Another problematic issue resulting from this outer current feedback loop is its proneness to loss of stability in the system. Therefore, defining the stability margins for this control system is of high importance. 
The stability analysis of the proposed system has not been presented in the literature. Generally, the stability analysis is an important issue in control systems which is why it is shared by some researchers [8,22-24,28]. Not only does it present the impact of particular parameters on the system stability but it also allows defining the range of their possible changes in such a way as to avoid the loss of stability. There are very little papers focusing on the stability analysis of an APF with external closed-loop control from the supply current. Existing ones, such as [22,23], do not involve predictive solutions; therefore, such an analysis seems to be important to introduce. Although the significance of such an analysis is considerable, conducting it can be complicated. Therefore, the introduction of some simplification is often demanded, especially in systems with complex structures.

The main subject of this paper is the stability analysis of a three-phase shunt APF with an implemented control system with an additional predictive outer control loop of the upstream current with predictive control of this current. This includes defining transfer functions of the system and examining the impact of the sampling period value, control system parameters and the accuracy of coupling circuit parameter identification on the system stability.

The paper is divided into five sections. Section 2 presents a circuit structure, a description of the implemented control and the parameters of the discussed system. Then, sample waveforms to illustrate the operation and a harmonic currents compensation level realized by the proposed shunt APF are presented. Section 3 focuses on the stability analysis of the system with the defining partial and overall transfer functions of the control system. Section 4 depicts root locations as a function of the changes in the particular control system's parameter values and defines the margins of the system stability for this system. The paper ends with a brief conclusion summarizing the significant contributions of the work in Section 5.

\section{Proposed Control System}

The presented system is a shunt APF which is connected in parallel between the supply and the load. Its circuit structure along with detailed parameters and proposed control strategy is described below.

\subsection{System Description}

The system under study is a three-phase, three-wire low-voltage power grid with a non-linear load connected to the grid via $L_{L}$ inductors. The load consists of a three-phase rectifier with the $R L$ load on the DC side of this converter. The implemented shunt APF comprises a two-level voltage source inverter (VSI), which acts as a controlled current source, connected to the grid between the source and the load in the PCC via a coupling circuit. An $L C L$ circuit was applied to ensure the attenuation of current ripples which are caused by the impulse operation of the converter. The proposed main circuit topology, which is a diagram of the tested system, is shown in Figure 1. The parameters in the figure indicate the following: $i_{\mathrm{u}}$-upstream current, $i_{\mathrm{d}}$-downstream current, $i_{1}-L_{1}$ current, $i_{2}$ $=i_{\mathrm{k}}-L_{2}$ current. The values of the circuit's parameters along with the parameters of the control are presented in Table 1. 


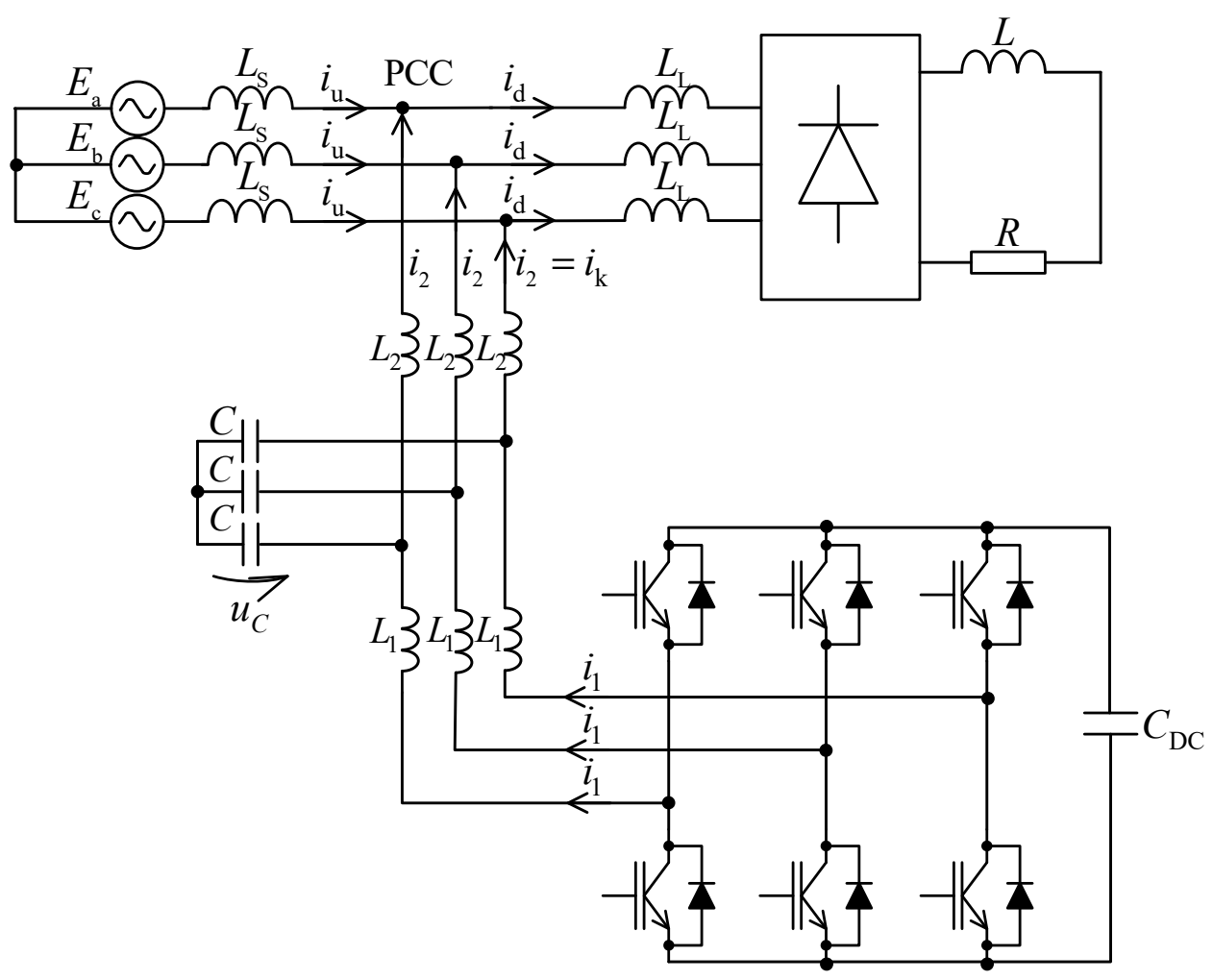

Figure 1. Main circuit structure.

Table 1. Parameters of proposed system.

\begin{tabular}{cc}
\hline Parameter & Value \\
\hline Line to line grid voltage & $3 \times 400 \mathrm{~V}$ \\
Grid frequency & $f=50 \mathrm{~Hz}$ \\
Grid inductance & $L_{\mathrm{S}}=40 \mu \mathrm{H}$ \\
Non-linear load & $L_{\mathrm{L}}=40 \mu \mathrm{H}$ \\
Non-linear load inductor & 6-pulse diode bridge with $R L$ load $(R=0.7 \Omega, L=1.0 \mathrm{mH})$ \\
LCL circuit & $120 \mathrm{kVA}$ \\
APF rated power & $3.0 \mu \mathrm{s}$ \\
Deadtime (uncompensated) & $1.5 \mathrm{~V}$ \\
IGBT voltage drop & \\
(uncompensated) & $1.0 \mathrm{~V}$ \\
Diode voltage drop & $\mu \mathrm{H}, L_{2}=75 \mu \mathrm{H}, \mathrm{C}=100 \mu \mathrm{F}$ \\
(uncompensated) & $f_{\mathrm{PWM}}=8 \mathrm{kHz}$ \\
PWM carrier frequency & $f_{\mathrm{s}}=16 \mathrm{kHz}$ \\
Sampling frequency &
\end{tabular}

The selection of the $L C L$ circuit parameter values as well as the value of the sampling period was performed in accordance with the methodology proposed in [8].

\subsection{Control Structure}

The proposed control system is a predictive closed-loop control of the shunt APF which utilizes the outer control loop of the upstream current with simultaneous realization of the control of this current. Its main units include the $u_{\mathrm{DC}}$ controller, which serves the superordinate function in the system, the predictive set current determination unit, the predictive current controller and the space vector pulse width modulation (SVPWM) modulator. The system's block diagram is presented in Figure 2. 


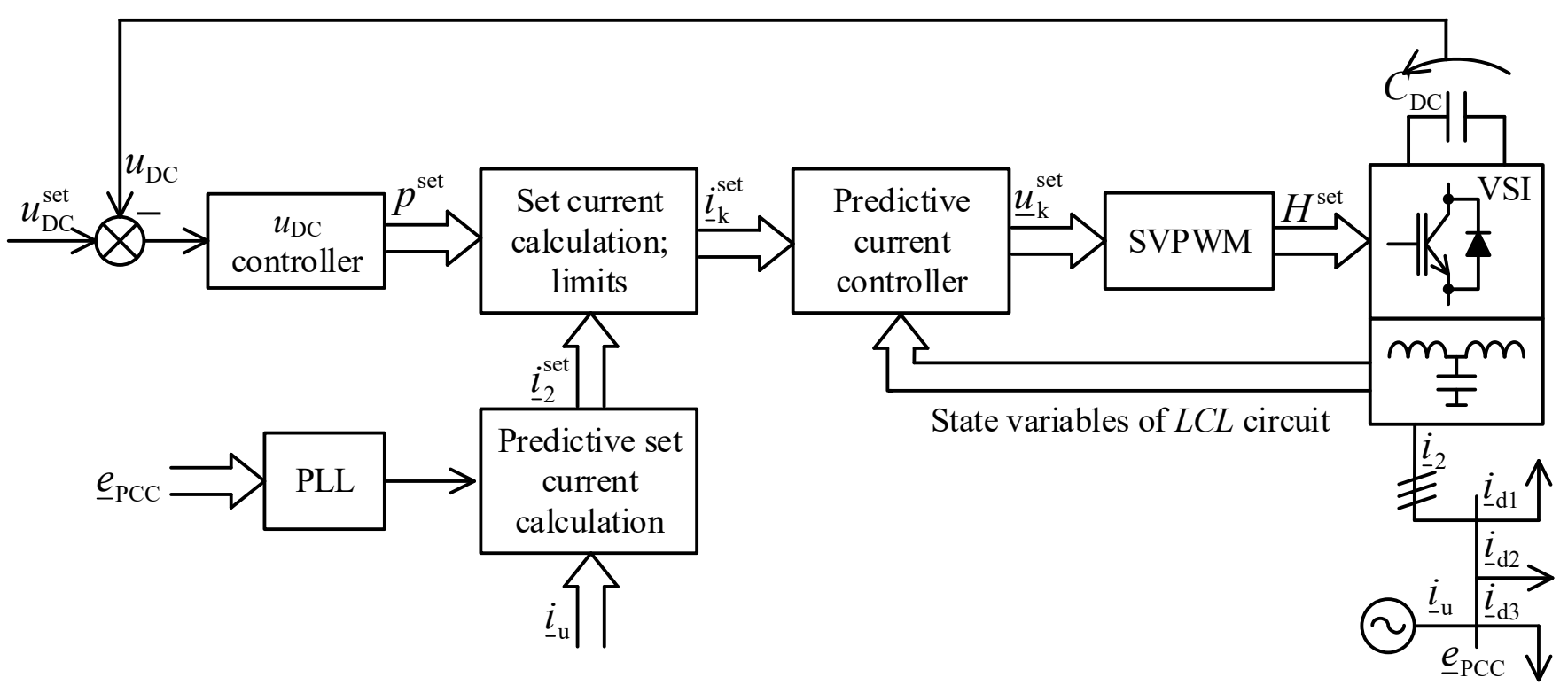

Figure 2. Block diagram of the control system.

The implemented control algorithm is developed in the orthogonal stationary reference frame projected on the complex plane $\alpha$-j $\beta$ with the usage of the Clarke transform with power invariance. The application of prediction demands the use of the predictive current controller, which provides correction of delays between the feedbacks and control, prediction of the supply voltage and prediction of the reference current.

The outer control loop of the upstream current is predictive and determines the APF reference current in a selective manner. It was set to allow compensating harmonic currents whose orders are equal to $\pm(6 k \pm 1)$, up to the 50 th harmonic. The particular reference harmonic current calculation, which is shown as a block diagram in Figure 3, includes the discrete Fourier transform (DFT), PI control, inverse discrete Fourier transform (IDFT) and prediction. The outer PI controllers, which are independent for each of the compensated current harmonics, control the complex amplitudes of these current harmonics to be equal to zero (separately, their orthogonal real and imaginary components), which are constant for the quasi-steady state of the compensated non-linear loads. Therefore, the task of these outer PI controllers is to completely eliminate the compensated current harmonics from the upstream current thanks to the action of its integral parts. The dynamics of these outer loop PI current controllers determine only the APF response time for changes in the power of compensated loads. They substantially improve the APF current compensation effectiveness in quasi-steady states, regardless of the dynamics of the inner current controller. Particular symbols appearing in the figure, not mentioned before, indicate: $\varphi_{\mathrm{e}, 1}$-the instantaneous phase angle of the supply voltage fundamental harmonic, $k$ - the order of harmonic current to be compensated, $r$-prediction horizon, $n$-sample number.

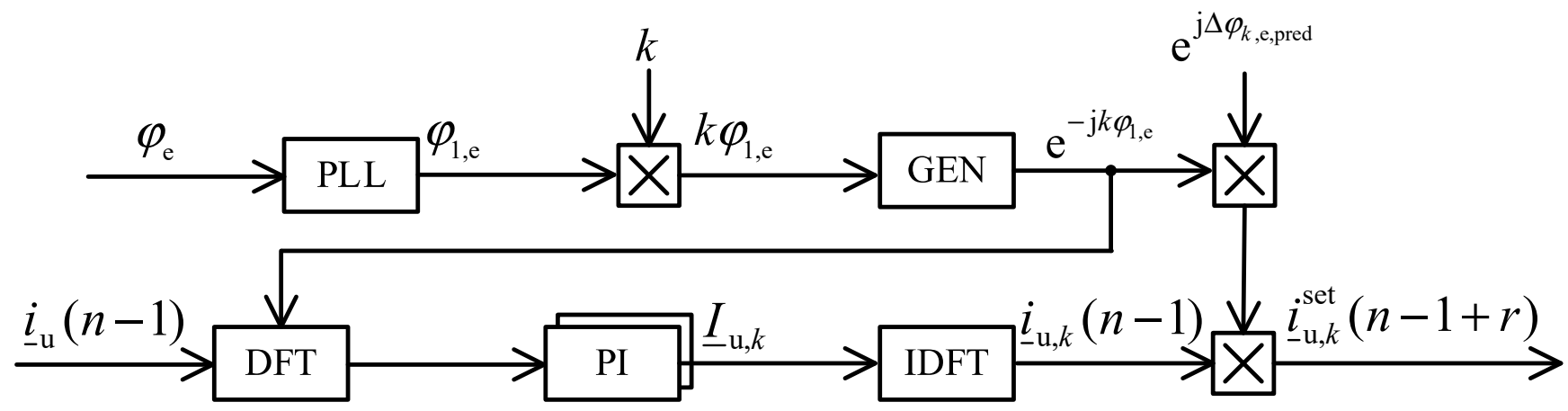

Figure 3. Block diagram of the determination of the particular current harmonic to be compensated. 
The resultant reference current is a superposition of the currents of individual harmonics determined in accordance with the diagram shown in Figure 3. The applied prediction horizon is equal to 3 on account of the fact that $L C L$ is a third-order circuit. It means that zero error of the set current is possible to achieve in a discrete control system in three control steps, which corresponds to three sampling periods $T_{\mathrm{s}}$.

\subsection{Sample Waveforms}

The discussed system, whose structure is presented in Figure 1, was examined in the simulation tests conducted in the PLECS software. The control system, shown in Figure 2, and the diagram for the outer control loop of the upstream current, determining the APF's reference current, which is depicted in Figure 3, were implemented as an algorithm written in the $C$ programming language. The simulation tests were conducted taking into consideration the feedback path from the upstream current, delays between the feedback and the control and the non-linearities resulting from the impulse operation of the converter. The presented results, which are depicted in Figures 4 and 5, were achieved for the system's parameters given in Table 1. Figure 4 shows waveforms in the PCC when there is no harmonic compensation in the system, whilst Figure 5 presents the transients when the APF is enabled.

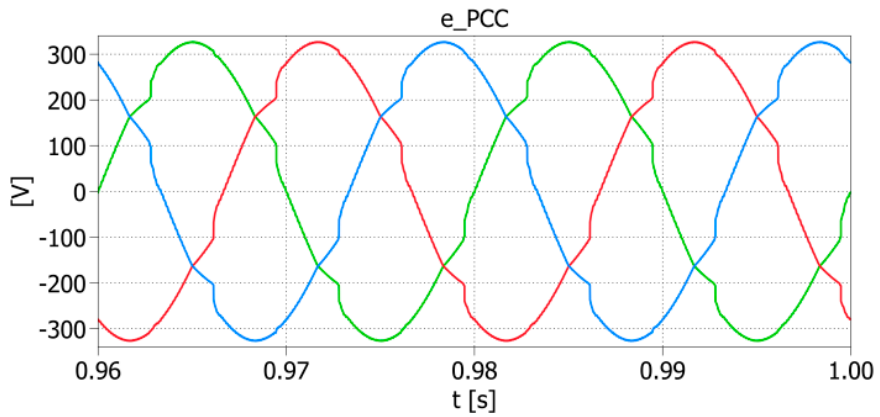

(a)

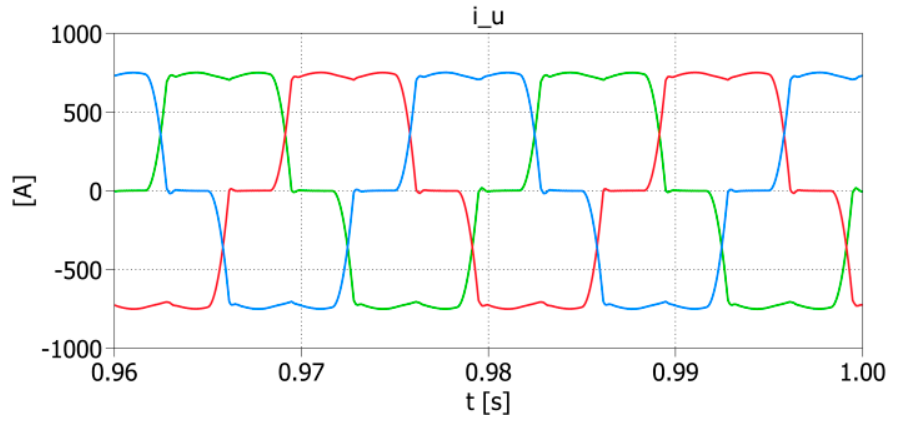

(b)

Figure 4. Harmonic compensation disabled: (a) voltage waveform in the PCC; $\mathrm{THD}_{\mathrm{u}}=5.11 \%$; (b) upstream current waveform in the PCC; $\mathrm{THD}_{\mathrm{i}}=23.42 \%$.

The above results prove that the proposed control strategy provided a high level of harmonic current limitation, which resulted, consequently, in voltage harmonics mitigation. $\mathrm{THD}_{\mathrm{i}}$ decreased about twenty-seven times, whereas $\mathrm{THD}_{\mathrm{u}}$ decreased almost four and a half times. Moreover, waveforms depicted in Figure $5 c, d$ reflect the effect of the influence of the LCL circuit on the system. The ripples contained in the APF current observed in Figure $5 \mathrm{c}$ and related to pulse modulation were reduced almost completely, which can be noticed in Figure 5d.

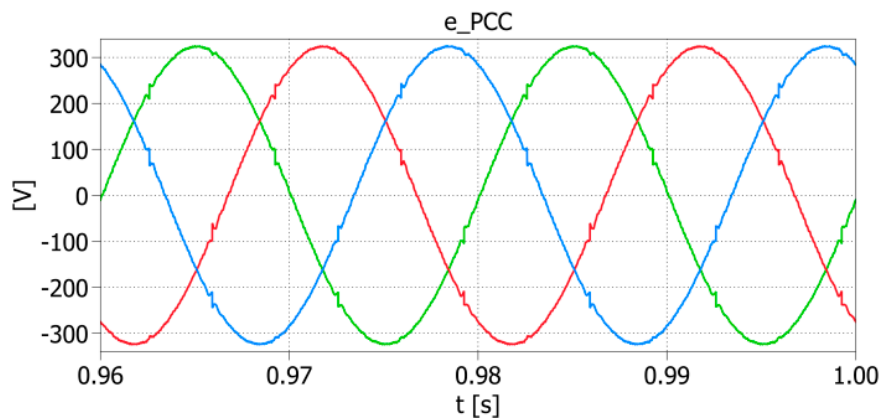

(a)

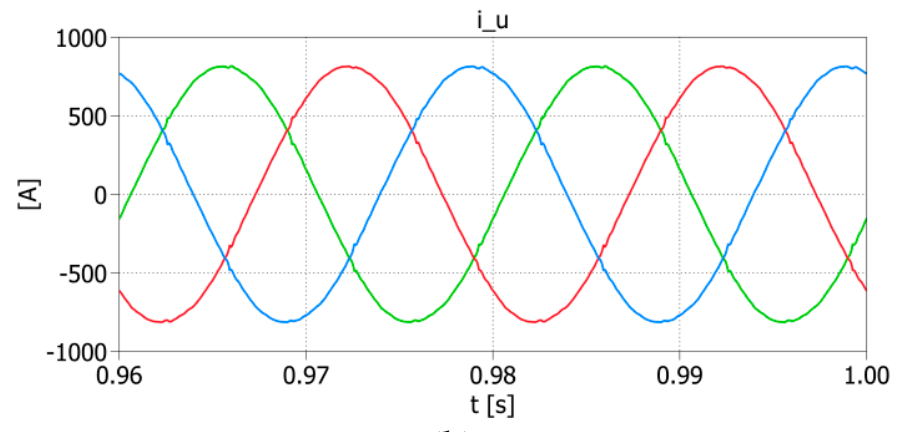

(b)

Figure 5. Cont. 


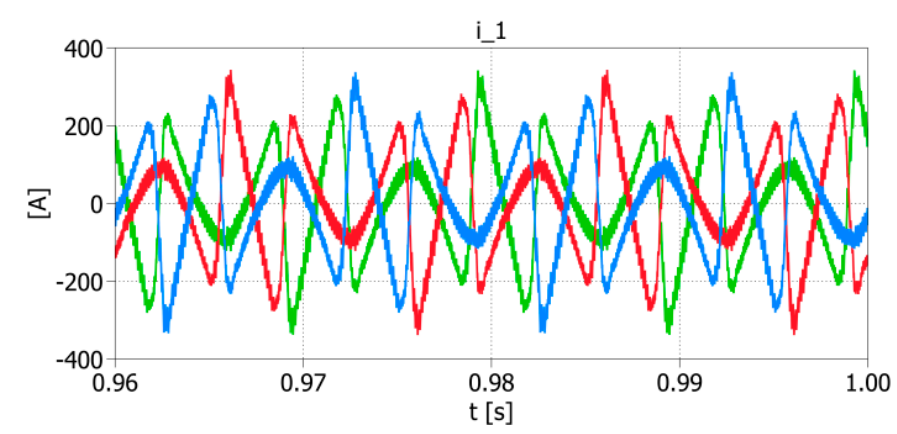

(c)

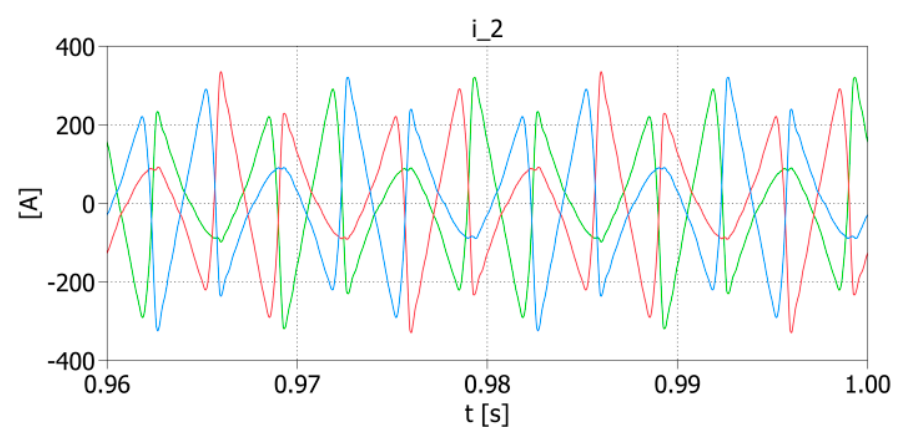

(d)

Figure 5. Harmonic compensation enabled: (a) voltage waveform in the PCC; $\mathrm{THD}_{\mathrm{u}}=1.17 \%$; $(\mathbf{b})$ upstream current waveform in the PCC; $\mathrm{THD}_{\mathrm{i}}=0.87 \%$; (c) $L_{1}$ current waveform $\left(i_{1}\right)$; (d) $L_{2}$ current waveform $\left(i_{2}=i_{\mathrm{k}}\right)$.

Figure 6 shows examples of waveforms obtained for the laboratory model. They illustrate the effectiveness of the predictive controller along with the current and voltage prediction algorithms. The presented laboratory system is a three-phase low-voltage power network $(400 \mathrm{~V}, 50 \mathrm{~Hz})$ and a non-linear load of apparent power equal to $10.3 \mathrm{kVA}$, in the form of a diode rectifier with an $R C$ load on the DC side. A shunt active power filter with rated power equal to $10 \mathrm{kVA}$ was connected between the supply network and the load via an $L C L$ circuit with the following parameters: $L_{1}=2.0 \mathrm{mH}, L_{2}=1.4 \mathrm{mH}, C=10 \mu \mathrm{F}$.

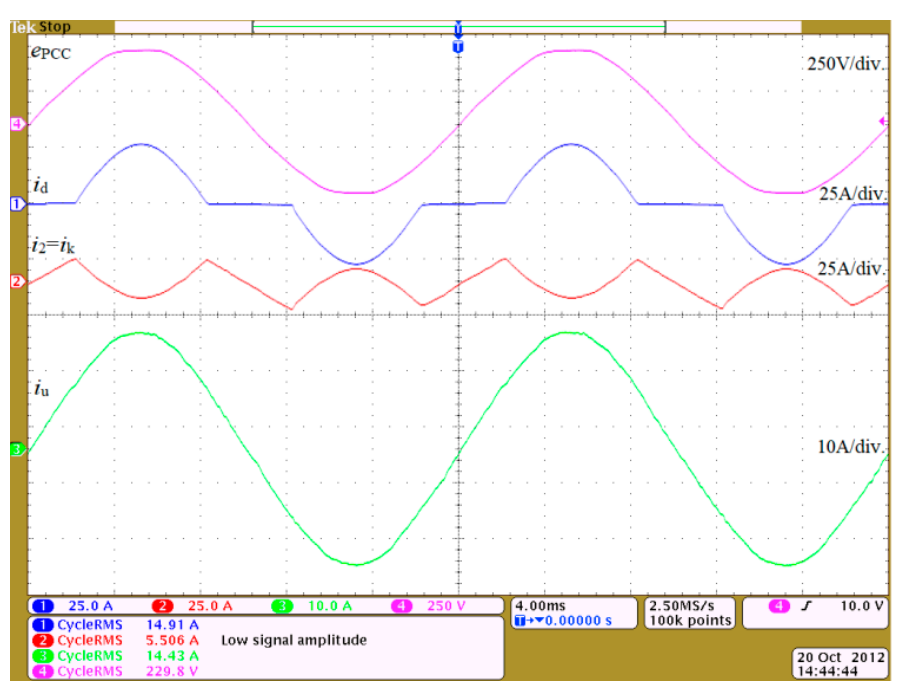

(a)

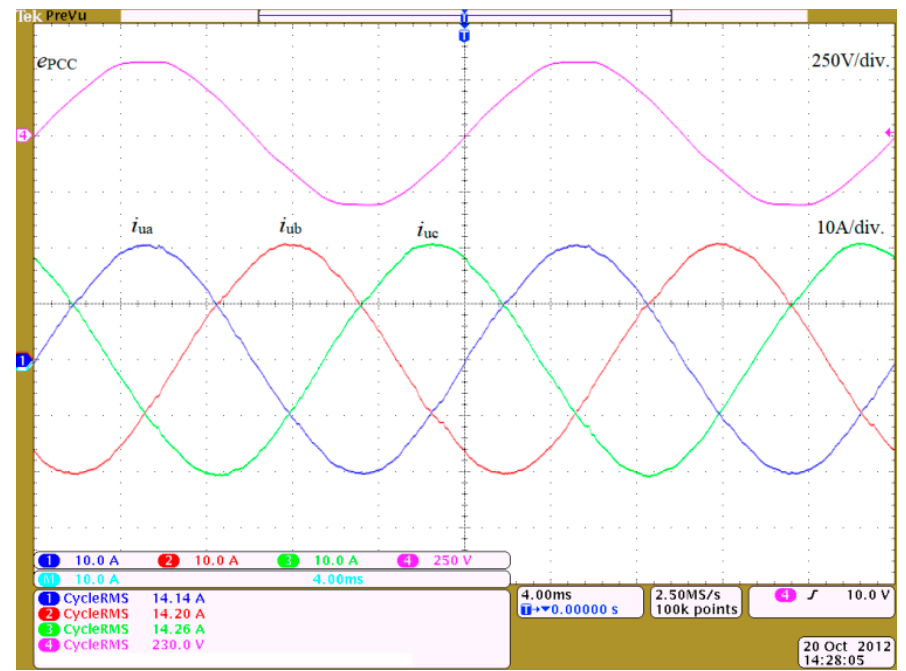

(b)

Figure 6. Oscillograms of the following waveforms: (a) from the top: voltage in the PCC, downstream current, APF current, upstream current in the PCC; (b) from the top: voltage in the PCC, three phases of the upstream current in the PCC.

The value of the $\mathrm{THD}_{\mathrm{i}}$ coefficient of the upstream current was equal to $44 \%$ with disabled compensation in the system. The results achieved when the APF was enabled show that the upstream current distortion was compensated to $\mathrm{THD}_{\mathrm{i}}=2.5 \%$, whilst the value of the $\mathrm{THD}_{\mathrm{u}}$ coefficient was compensated to $1.69 \%$.

\section{Stability Analysis}

The subject of the stability analysis is the control system with the outer closed-loop current reference control, inner model-based predictive current controller and an object in the form of an $L C L$ coupling circuit, an ideal grid voltage source and a current source-based load. The current controller requires both the information about state variables of the $L C L$ circuit and the reference current signal for proper operation. Such a system is prone to the loss of stability in case of operating with an improper control sampling frequency 
and poor identification of the $L C L$ circuit parameters required by the MPC controller. The presence of the outer control loop results in additional roots of the characteristic equation of the system. As the proposed control system is not designed to be adaptive, its important quality factor is the robustness. Due to the relatively high complexity of the system, certain simplifications were adopted for the need to perform this analysis. Performing the stability analysis demanded defining particular transfer functions of the system first and then determining their generalization. These operations as well as the stability analysis were performed with the utilization of MATLAB software with the following toolboxes: System Identification Toolbox, Control System Toolbox and Symbolic Math Toolbox.

\subsection{Assumptions}

The stability analysis was conducted with the presumption that the grid is ideally stiff, and thus operation under conditions of a weak grid is not considered in this paper. The discussed system is based on the discrete-continuous model, in which the applied predictive current controller is the discrete part, and the continuous parts are the voltage inverter and the $L C L$ circuit. Therefore, the stability analysis of the entire system is possible only when it is reduced to either a continuous or a discrete form. However, reducing it to the discrete form allows the stability analysis as a function of the sampling frequency, which constitutes an essential parameter of the system as it affects the stability of the control system. On account of that, continuous parts were discretized and the whole system was examined in the $z$-domain. Furthermore, the model of the inverter was linearized and simplified. Assuming an unlimited $u_{\mathrm{DC}}$ voltage and neglecting the inverter's nonlinearities, there is an opportunity to adopt a linear model of the inverter as a zero-order hold $(\mathrm{ZOH})$.

\subsection{Overall and Partial Transfer Functions}

Figure 7 presents the $z$-domain block diagram of the proposed system with compensation for a particular harmonic current. This scheme contains all considered partial transfer functions, whilst equivalent block diagrams with generalized transfer functions are depicted in Figure 8. All symbols utilized both in diagrams and transfer functions are consistent with those used in the previous figures, tables and text.

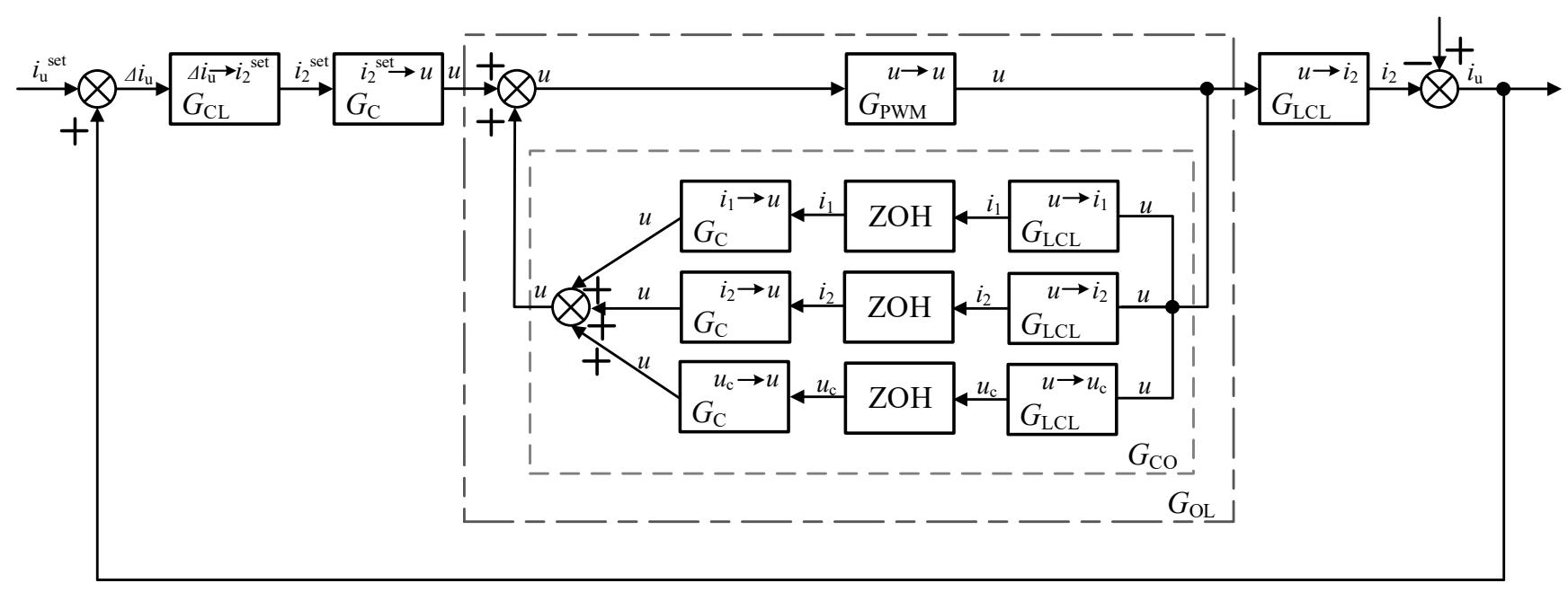

Figure 7. Z-domain control block diagram. 


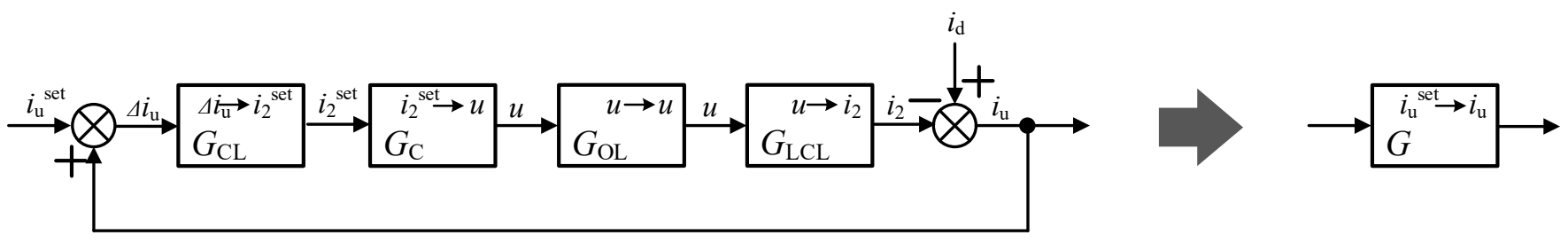

Figure 8. Z-domain equivalent control block diagrams.

The discrete transfer function matrix of the predictive model-based current controller derives from difference equations described in detail in [8] and is as follows:

$$
G_{\mathrm{C}}(z)=\left[\begin{array}{c}
G_{C, i_{1} \rightarrow u}(z) \\
G_{C, i_{2} \rightarrow u}(z) \\
G_{C, u_{c} \rightarrow u}(z) \\
G_{C, i_{2} \operatorname{set} \rightarrow u}(z)
\end{array}\right]=\left[\begin{array}{c}
\frac{-3 L_{1}^{2} L_{2} C^{2}+\left(L_{1}^{2} C+4 L_{1} L_{2} C\right) T_{s}^{2}-\left(L_{1}+L_{2}\right) T_{s}^{4}}{2 L_{1} L_{2} T_{s}^{2} T_{s}-L_{2} C T_{s}^{3}+C^{2} L_{1} L_{2} T_{s} \cdot z} \\
\frac{2 L_{1}^{2} L_{2} C^{2}-\left(L_{1}^{2} C+4 L_{1} L_{2} C\right) T_{s}^{2}+\left(L_{1}+L_{2}\right) T_{s}^{4}}{2 L_{1} L_{2} T^{2} T_{s}-L_{2} C C_{s}^{3}+C^{2} L_{1} L_{2} T_{s} \cdot z} \\
\frac{L_{1}^{2} L_{2} C^{2}-\left(C L_{1}^{2} C+3 L_{2} L_{2} C\right) T_{s}^{2}\left(L_{1}+L_{2}\right) T_{s}^{4}}{\left(L_{2} T_{s}^{4}-2 C L_{1} L_{2} T_{s}^{2}\right) z-C L_{1} L_{2} T_{s}^{2} \cdot z^{2}} \\
\frac{L_{1}^{2} L_{2} C^{2} \cdot z^{3}-L_{1}^{2} L_{2} C^{2} \cdot z^{2}+L_{1}^{2} C T_{s}^{2} \cdot z^{2}}{2 L_{1} C T_{s}^{3}-T_{s}^{5}+C L_{1} T_{s}^{3} \cdot z}
\end{array}\right]^{T},
$$

where $T_{\mathrm{s}}$ denotes the sampling period.

The discrete transfer function matrix of the $L C L$ circuit (analog part of the system) results from the cascade connection of the $\mathrm{ZOH}$, which reflects the pulse operation of the APF inverter, and the $L C L$ continuous transfer function matrix derived from differential equations of the $L C L$ coupling circuit outlined in [8]. Therefore, the $G_{\mathrm{LCL}}(z)$ matrix is described by the following equation:

$$
G_{\mathrm{LCL}}(z)=\left[\begin{array}{c}
G_{\mathrm{LCL}, u \rightarrow i_{1}}(z) \\
G_{\mathrm{LCL}, u \rightarrow i_{2}}(z) \\
G_{\mathrm{LCL}, u \rightarrow u_{c}}(z)
\end{array}\right]=\left[\begin{array}{c}
\frac{L_{1} \omega_{\mathrm{r}} T_{\mathrm{s}}\left(z^{2}-2 \cos \left(\omega_{\mathrm{r}} T_{\mathrm{s}}\right) z+1\right)+L_{2} \sin \left(\omega_{\mathrm{r}} T_{\mathrm{s}}\right)\left(z^{2}-2 z+1\right)}{L_{1} \omega_{\mathrm{r}}(z-1)\left(L_{1}+L_{2}\right)\left(z^{2}-2 \cos \left(\omega_{\mathrm{r}} T_{\mathrm{T}}\right) z+1\right)} \\
\frac{\omega_{\mathrm{r}} T_{\mathrm{s}}\left(z^{2}-2 \cos \left(\omega_{\mathrm{r}} T_{\mathrm{s}} z+1\right)-\sin \left(\omega_{\mathrm{r}} T_{\mathrm{s}}\left(z^{2}-2 z+1\right)\right.\right.}{\omega_{\mathrm{r}}(z-1)\left(L_{1}+L_{2}\right)\left(z^{2}-2 \cos \left(\omega_{\mathrm{r}} T_{\mathrm{S}}\right) z+1\right)} \\
\frac{L_{2}\left(1-\cos \left(\omega_{\mathrm{r}} T_{\mathrm{s}}\right)(z+1)\right.}{\left(L_{1}+L_{2}\right)\left(z^{2}-2 \cos \left(\omega_{\mathrm{r}} T_{\mathrm{s}}\right) z+1\right)}
\end{array}\right]
$$

where $\omega_{\mathrm{r}}$ is the $L C L$ resonant angular frequency:

$$
\omega_{\mathrm{r}}=\sqrt{\frac{L_{1}+L_{2}}{L_{1} L_{2} C}}
$$

while the resonant frequency is expressed by

$$
f_{\mathrm{r}}=\frac{\omega_{\mathrm{r}}}{2 \pi}=\frac{1}{2 \pi} \sqrt{\frac{L_{1}+L_{2}}{L_{1} L_{2} C}}
$$

which in the discussed system is equal to $f_{\mathrm{r}}=2.25 \mathrm{kHz}$.

$G_{C L}(z)$ is the set current transfer function. Determining the reference current in the presented circuit requires transforming the signal into the frequency domain with the usage of the DFT. From a mathematical point of view, this operation is identical to the Park transform, where the angle of rotation is the product of the order of a given harmonic and the instantaneous angle of the grid voltage obtained from the phase-locked loop (PLL), followed by low-pass filtering. The next steps consist of PI control, prediction and the IDFT, 
which is the same as the inverse Park transform. Bearing this in mind, the $G_{\mathrm{CL}}(z)$ matrix derives from the following equation:

$$
\begin{array}{r}
G_{\mathrm{CL}}(z)=\left[\begin{array}{cc}
\cos (\varphi k) & \sin (\varphi k) \\
-\sin (\varphi k) & \cos (\varphi k)
\end{array}\right] \cdot\left[\begin{array}{cc}
G_{\mathrm{LPF}}(z) & 0 \\
0 & G_{\mathrm{LPF}}(z)
\end{array}\right] \cdot\left[\begin{array}{cc}
G_{\mathrm{PI}}(z) & 0 \\
0 & G_{\mathrm{PI}}(z)
\end{array}\right] \\
\cdot\left[\begin{array}{cc}
G_{\text {pred }}(z) & 0 \\
0 & G_{\text {pred }}(z)
\end{array}\right] \cdot\left[\begin{array}{cc}
\cos (\varphi k) & -\sin (\varphi k) \\
\sin (\varphi k) & \cos (\varphi k)
\end{array}\right]
\end{array}
$$

where $\varphi$ and $k$ denote the instantaneous phase angle of the supply voltage fundamental harmonic and the order of the compensated harmonic current, respectively.

In the case where the matrices between the Park transforms are diagonal with the same coefficients on the main diagonal, the Park transform matrices do not affect the value of the resultant matrix. This is because the product of Park transform matrices is the identity matrix:

$$
\left[\begin{array}{cc}
\cos (\varphi k) & \sin (\varphi k) \\
-\sin (\varphi k) & \cos (\varphi k)
\end{array}\right] \cdot\left[\begin{array}{cc}
\cos (\varphi k) & -\sin (\varphi k) \\
\sin (\varphi k) & \cos (\varphi k)
\end{array}\right]=\left[\begin{array}{ll}
1 & 0 \\
0 & 1
\end{array}\right]
$$

Therefore, the final transfer function can be expressed by

$$
G_{\mathrm{CL}}(z)=G_{\mathrm{LPF}}(z) \cdot G_{\mathrm{PI}}(z) \cdot G_{\text {pred }}(z),
$$

and is represented as follows:

$$
G_{\mathrm{CL}}(z)=\frac{a\left(K_{\mathrm{p}} \cdot z-K_{\mathrm{p}}+K_{\mathrm{i}} T_{\mathrm{s}}\right)}{z^{2} \cdot(z-1)(a+z-1)}
$$

where $a$ is the coefficient of the low-pass filter, while $K_{\mathrm{p}}$ and $K_{\mathrm{i}}$ denote proportional and integral coefficients of the PI controller.

The whole system is reduced to the single-input, single-output (SISO) form, as it is shown in Figure 8. On account of that, the overall transfer function is represented as

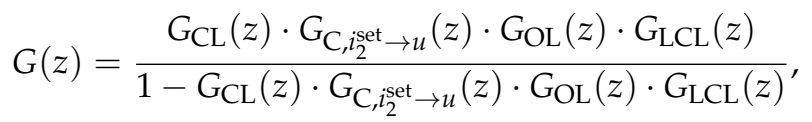

with $G_{\mathrm{OL}}(z)$ expressed by the following equation:

$$
G_{\mathrm{OL}}(z)=\frac{G_{\mathrm{PWM}}(z)}{1-G_{\mathrm{PWM}}(z) \cdot G_{\mathrm{CO}}(z)}=\frac{1}{1-G_{\mathrm{CO}}(z)},
$$

where the minus in the denominator results from taking into account the negative feedbacks in the transfer function of the current controller.

\section{Results}

The stability of the considered control system results from the root locations of the characteristic equation of the $G(z)$ transfer function on the $z$-plane. In the discussed APF circuit, it is conditioned by the value of the sampling period, the $K_{\mathrm{p}}$ and $K_{\mathrm{i}}$ coefficients and the identification accuracy of the $L C L$ coupling circuit parameters. The latter aspect is especially significant when the applied current controller is predictive. To examine the impact of this factor on stability, the exact parameters $L_{1}, L_{2}$ and $C$ in the predictive controller transfer function $G_{C}(z)$ were replaced with the identified (measured or estimated) values $L_{1 \mathrm{c}}, L_{2 \mathrm{c}}$ and $C_{\mathrm{c}}$, respectively. This results from the fact that parameters of the $L C L$ circuit implemented in the control algorithm $\left(L_{1 c}, L_{2 c}, C_{c}\right)$ constitute the parameters of the current controller. Changes in their values, which determine the percentage accuracy of their compliance with the parameters of the $L C L$ circuit, as well as the range of values of changes in the $T_{\mathrm{s}}, K_{\mathrm{p}}$ and $K_{\mathrm{i}}$ parameters, define the area of stable operation of the system.

Root locus analyses of the APF feedback control system as a function of the abovementioned parameters are presented in Figure 9. Red crosses in each figure indicate the 
pole locations of the discussed system for the following parameters: $L_{1 \mathrm{c}}=L_{1}=150 \mu \mathrm{H}, L_{2 \mathrm{c}}$ $=L_{2}=75 \mu \mathrm{H}, C_{\mathrm{c}}=C=100 \mu \mathrm{F}, T_{\mathrm{s}}=6.25 .10^{-5} \mathrm{~s}, K_{\mathrm{p}}=0.02, K_{\mathrm{i}}=10.0$. The presented results were obtained from tests conducted in MATLAB software.

The spans of the permissible changes in the $K_{\mathrm{p}}$ and $K_{\mathrm{i}}$ coefficients in the area of system stability are below 1.08 and above 120 , respectively, when the other parameter remains unchanged. This control system was not tested under the conditions of changes in both coefficients simultaneously.

The control system is stable in terms of the sampling period value being below 7.38.10 ${ }^{-5} \mathrm{~s}$ and in the range from $1 \cdot 35 \cdot 10^{-4} \mathrm{~s}$ to $1 \cdot 5 \cdot 10^{-4} \mathrm{~s}$. These values correspond to the sampling frequency between 6.67 and $7.46 \mathrm{kHz}$ and above $13.55 \mathrm{kHz}$. The relation between the sampling frequency $f_{\mathrm{s}}$ and the modulation frequency $f_{\mathrm{PWM}}$ in the proposed system is as follows:

$$
f_{\mathrm{s}}=2 f_{\mathrm{PWM}},
$$

and thus the system remains stable when the modulator pulsation frequency is in the range from 3.33 to $3.73 \mathrm{kHz}$ and above $6.77 \mathrm{kHz}$. This means that the minimum sampling frequency within the stable area is approximately 1.5 times the $L C L$ circuit resonant frequency: $f_{\mathrm{PWM}}=$ $1.5 f_{\mathrm{r}}$. However, a relatively large margin of stability can be obtained when $f_{\mathrm{PWM}}>3 f_{\mathrm{r}}$.

As far as the changes in the identification accuracy of the $L C L$ coupling circuit parameters are concerned, the feedback control system remains stable for the given inductance value $L_{1 \mathrm{c}}$ in the range from $88 \%$ to $136 \%$ of the exact value $\left(L_{1}\right)$, for the inductance $L_{2 \mathrm{c}}$ above $64 \%$ of the exact value $\left(L_{2}\right)$ and for the capacitance $C_{\mathrm{c}}$ in the range from $74 \%$ to $290 \%$ of the exact value (C). Not only do these ranges far exceed the practical tolerances of the choke and capacitor parameters but they are also beyond the achievable accuracy of measurements of these quantities.

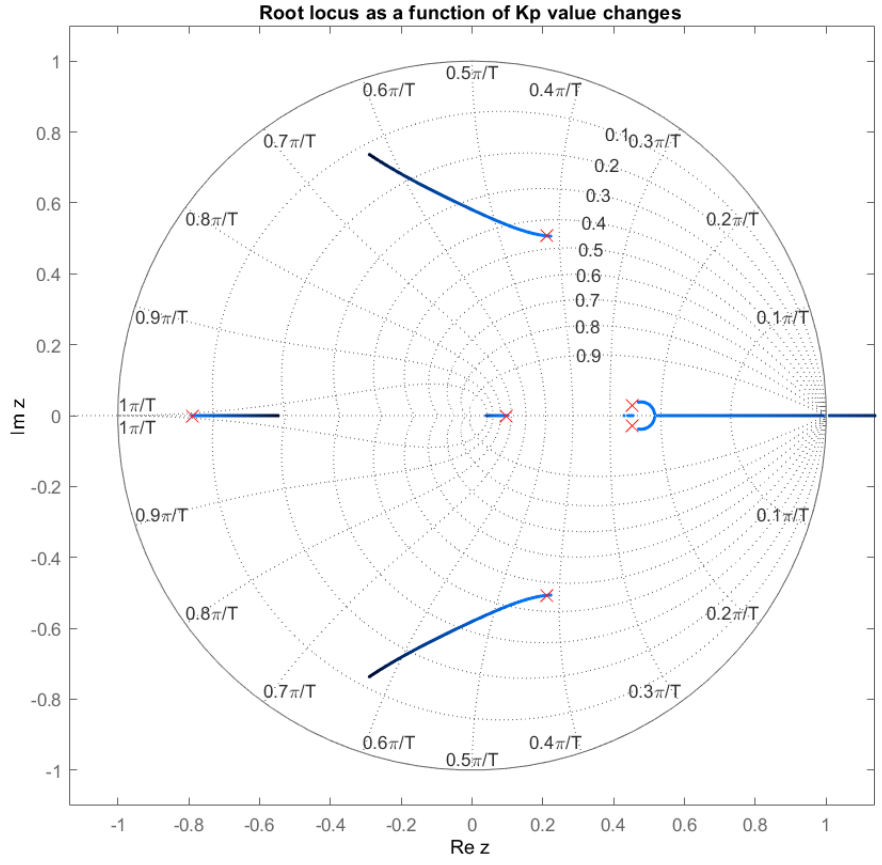

(a)

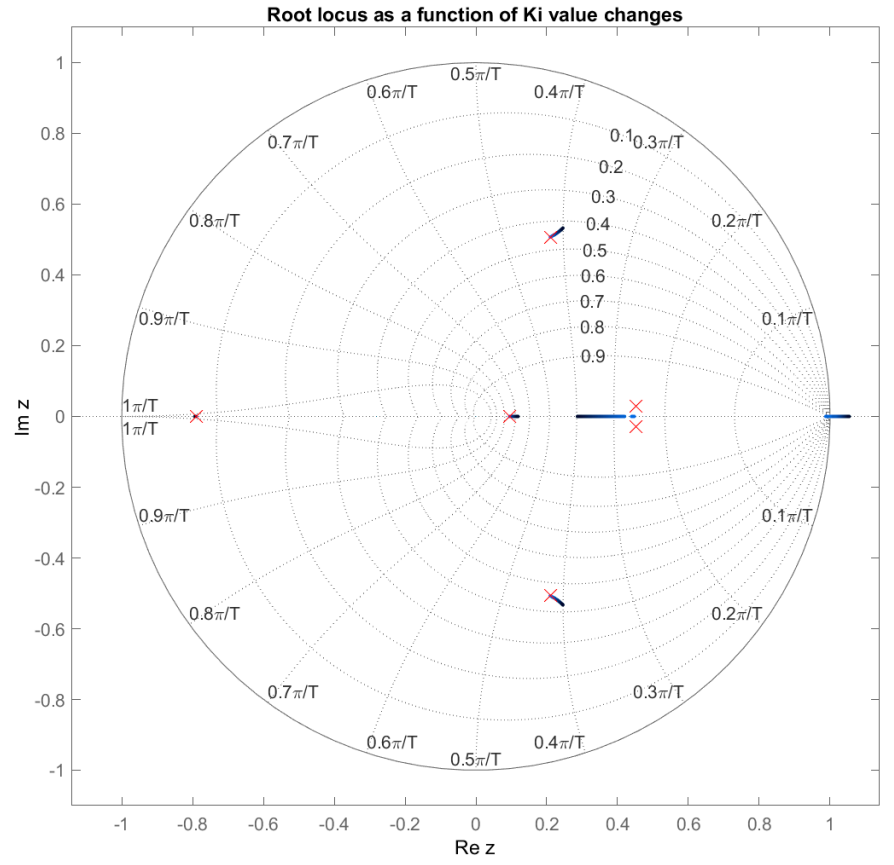

(b)

Figure 9. Cont. 


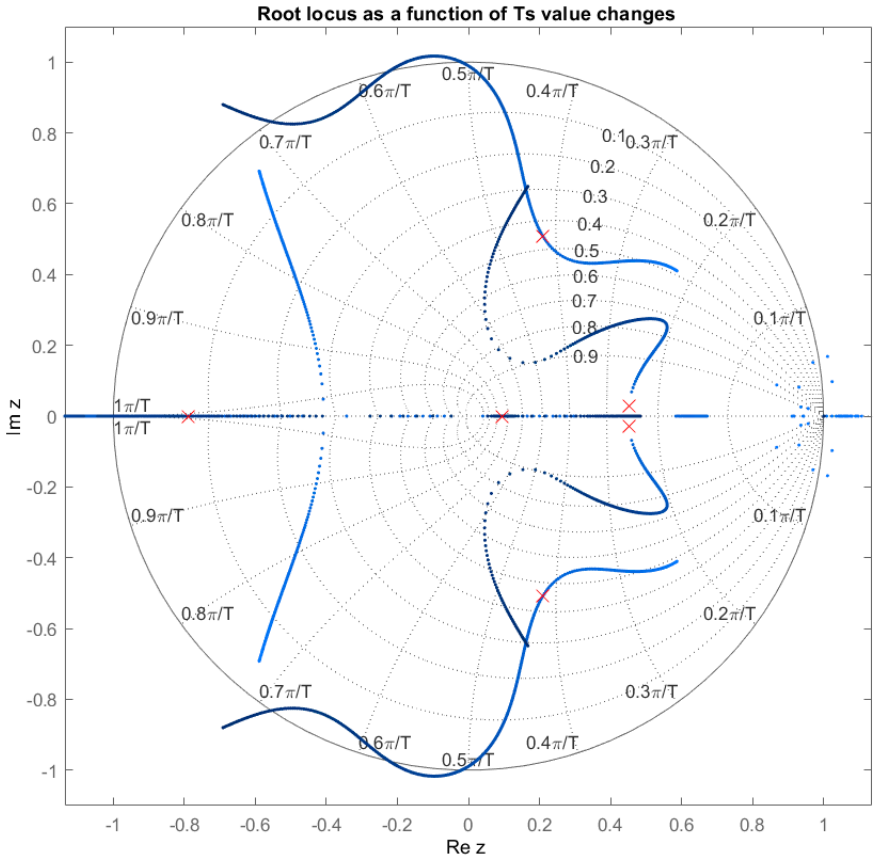

(c)

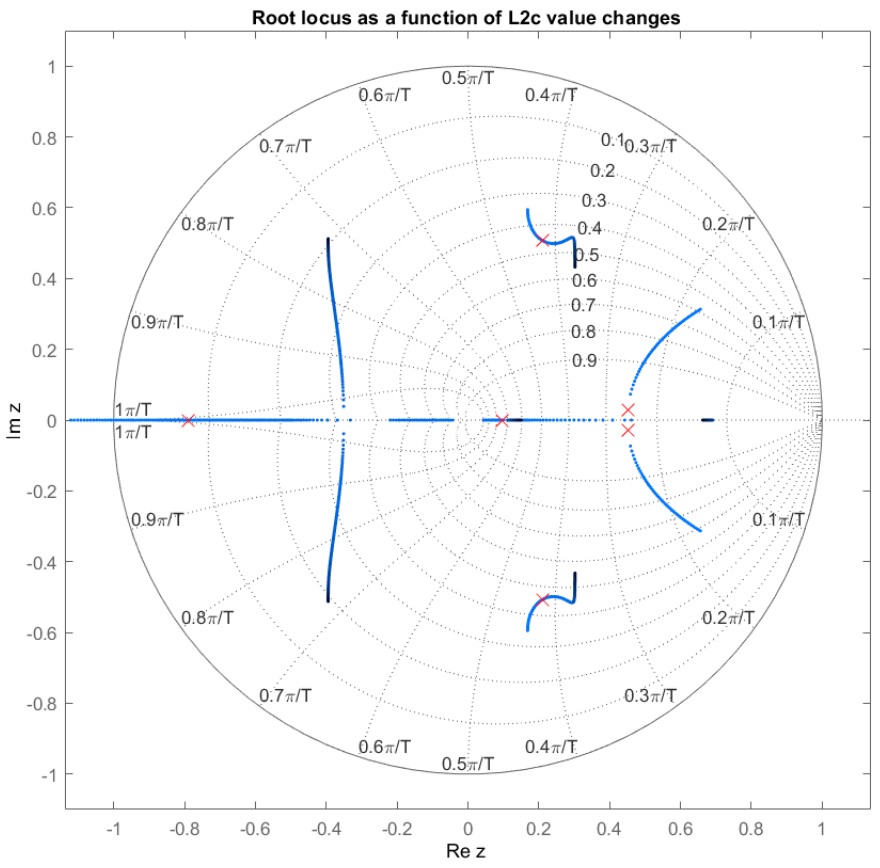

(e)

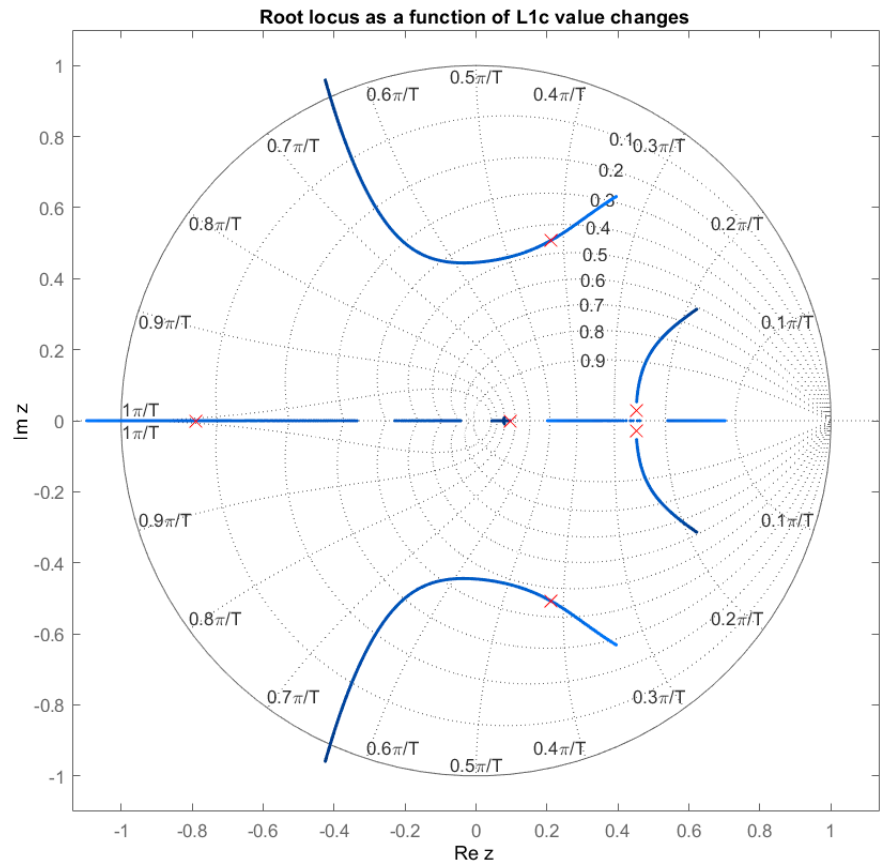

(d)

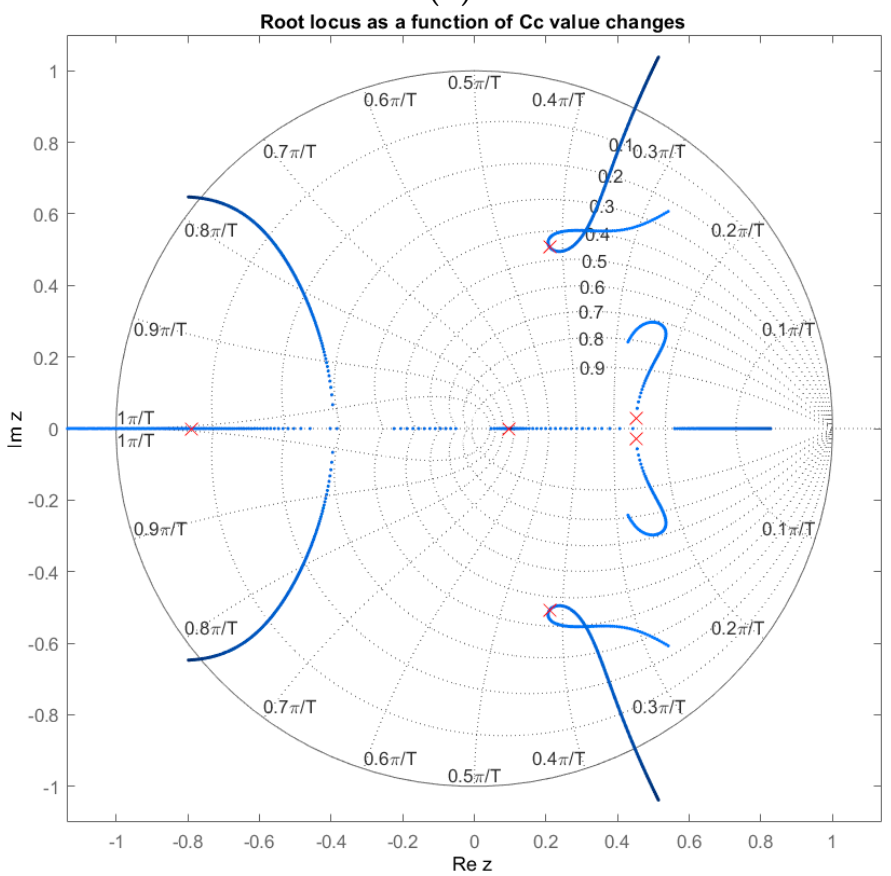

(f)

Figure 9. Results of the APF closed-loop control system stability analysis. Root locus as a function of the following parameter value changes: $K_{\mathrm{p}}(\mathbf{a}), K_{\mathrm{i}}(\mathbf{b}), T_{\mathrm{s}}(\mathbf{c}), L_{1 \mathrm{c}}(\mathbf{d}), L_{2 \mathrm{c}}(\mathbf{e}), C_{\mathrm{c}}(\mathbf{f})$.

Simulation tests were conducted in PLECS to define the values of the considered parameters, for which the loss of stability is observed in the control system. The simulated control system is stable when the value of the $L_{1 \mathrm{c}}$ parameter is within the range from $89 \%$ to $136 \%$ of the exact value $\left(L_{1}\right)$, the value of $L_{2 c}$ is above $64 \%$ of the exact value $\left(L_{2}\right)$ and the value of $C_{c}$ is between $74 \%$ and $325 \%$ of the exact value $(C)$. The loss of stability occurs when the sampling period is above $1.49 \cdot 10^{-4} \mathrm{~s}$ and in the range from $1.29 \cdot 10^{-4}$ to $7.38 .10^{-5}$ s. The obtained values are almost completely consistent with the values achieved in the stability analysis conducted in MATLAB, which makes the results reliable. 
Further tests performed for the determinants of the experimental system provided results which show that the stability regions for the examined parameters are wider than those obtained in the stability analysis. This is due to limits of the control signals which result from the value of the $u_{\mathrm{DC}}$ voltage (and, consequently, the range of the inverter $\mathrm{AC}$ voltage) as well as the value of the APF's maximum current. However, a relatively high consistency is obtained for the $T_{\mathrm{S}}$ parameter. It is an important issue on account of the fact that this parameter determines the value of the inverter modulation frequency $f_{\mathrm{PWM}}$, and in consequence, due to switching losses, the maximum rated power of the singleinverter-based APF. Although the system remains stable in a wide range of the mentioned parameter value changes, the compensation effectiveness beyond the stability region is noticeably lower, which is shown further in the paper. The comparison of the results obtained on the basis of the simulation tests, the stability analysis and tests performed for the determinants of the experimental system is presented in Table 2.

Table 2. Comparison of analytical and simulation stability limits of the system.

\begin{tabular}{ccccc}
\hline & $L_{\mathbf{1 c}}$ Parameter & $\boldsymbol{L}_{\mathbf{2} \text { c }}$ Parameter & $\boldsymbol{C}_{\mathbf{c}}$ Parameter & $\boldsymbol{T}_{\mathbf{s}}$ Parameter \\
\hline $\begin{array}{c}\text { Stability analysis } \\
\text { performed in } \\
\text { MATLAB }\end{array}$ & $\begin{array}{c}8 \% \div 136 \% \text { of } \\
L_{1}\end{array}$ & $>64 \%$ of $L_{2}$ & $74 \% \div 290 \%$ of $C$ & $\begin{array}{c}150 \div 135 \mu \mathrm{s} \\
\text { and }<73.8 \mu \mathrm{s}\end{array}$ \\
\hline $\begin{array}{c}\text { Simulation tests } \\
\text { conducted in } \\
\text { PLECS }\end{array}$ & $89 \% \div 136 \%$ of \\
$L_{1}$ & $>64 \%$ of $L_{2}$ & $74 \% \div 325 \%$ of $C$ & $\begin{array}{c}149 \div 130 \mu \mathrm{s} \\
\text { and }<73.8 \mu \mathrm{s}\end{array}$ \\
\hline $\begin{array}{c}\text { Tests performed } \\
\text { for the } \\
\text { determinants of } \\
\text { the experimental } \\
\text { system }\end{array}$ & $13 \% \div 214 \%$ of \\
$L_{1}$ & $>16 \%$ of $L_{2}$ & $24 \% \div 315 \%$ of $C$ & $<150 \mu \mathrm{s}$ \\
\hline
\end{tabular}

Presented results prove that the stability margins obtained by the analytical method ensure the stability in actual systems.

Sample waveforms of the APF current, measured on $L_{1}$ and $L_{2}$ inductances, illustrating the loss of stability are shown in Figure 10 . The values of parameters $L_{2 \mathrm{c}}$ and $C_{\mathrm{c}}$ are equal to parameters $L_{2}$ and $C$, respectively, given in Table 1 . The value of parameter $L_{1 \mathrm{c}}$ is changed in the time equal to $0.5 \mathrm{~s}$ from the value $L_{1 \mathrm{c}}=136 \%$ of $L_{1}$ to the value $L_{1 \mathrm{c}}=137 \%$ of $L_{1}$, which is the same as exceeding the stability limit shown in Table 2. The waveforms up to time $t=0.5 \mathrm{~s}$ present stable operation of the system, whilst the waveforms in the time ranges from 0.5 to $0.6 \mathrm{~s}$ depict the system's operation in case of loss of stability. The choice of the $L_{1 \mathrm{c}}$ parameter to represent the system stability loss results from the fact that the value of this parameter has the greatest impact on the system stability, which will be presented later in the paper.

The obtained results show that the greatest effects of the loss of stability in the control system are visible on the waveforms of currents $i_{1}$ and $i_{C}$ as they reached very high values. The value of the current $i_{2}$ is smaller due to the secondary influence of the resonance formed in the circuit $L_{1}-C$.

Figure 11 presents values of $\mathrm{THD}_{\mathrm{i}}$ in the PCC as a function of the $L C L$ circuit parameter identification. It completes previous results and shows the effectiveness of compensation performed by the APF in case of introducing $L C L$ parameters inaccurately in the control system. The presented characteristics are an approximation of the points obtained on the basis of a series of simulations, assuming that only one of the parameters is changed while the others are identified correctly and remain unchanged. The discussed parameters were tested within the following identification accuracy ranges: $L_{1 \mathrm{c}}: 30 \% \div 200 \%$ of $L_{1}, L_{2 \mathrm{c}}: 30 \%$ $\div 250 \%$ of $L_{2}, C_{\mathrm{c}}: 50 \% \div 200 \%$ of $C$. 


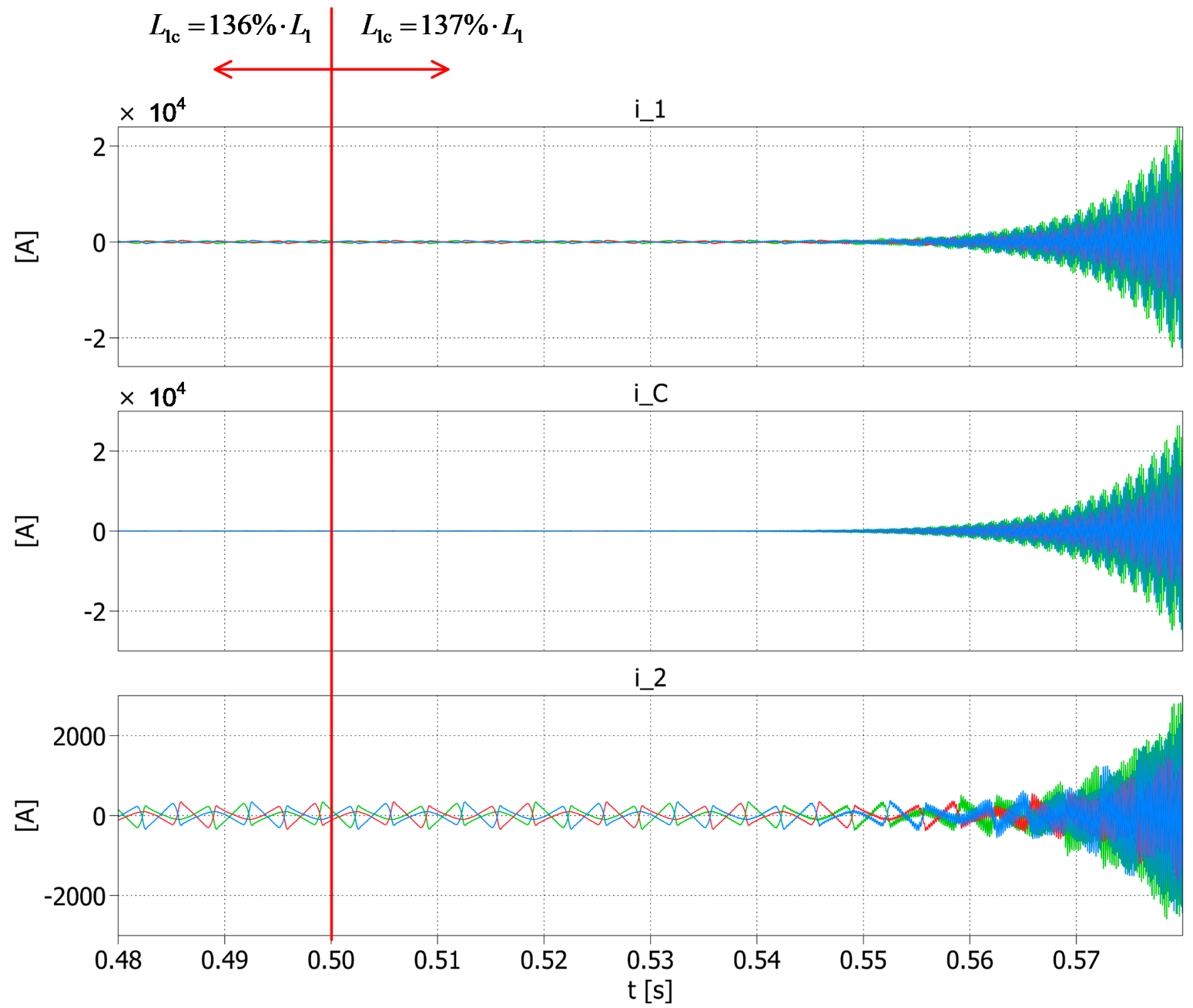

Figure 10. Loss of stability in the control system after changing the value of $L_{1 \mathrm{c}}$ parameter when $t=0.5 \mathrm{~s}$. From the top: $L_{1}$ current waveform $\left(i_{1}\right), C$ current waveform $\left(i_{C}\right), L_{2}$ current waveform $\left(i_{2}=i_{\mathrm{k}}\right)$.

The obtained results show that the optimal values of the current controller parameters $\left(L_{1 \mathrm{c}}, L_{2 \mathrm{c}}, C_{\mathrm{c}}\right)$, from the point of view of the compensation effectiveness determined on the basis of the THD coefficient, are the exact values of the $L C L$ circuit. It is also noticeable from the characteristics that the correctness of determining the value of inductance $L_{1}$ has the greatest impact on the quality of compensation. 


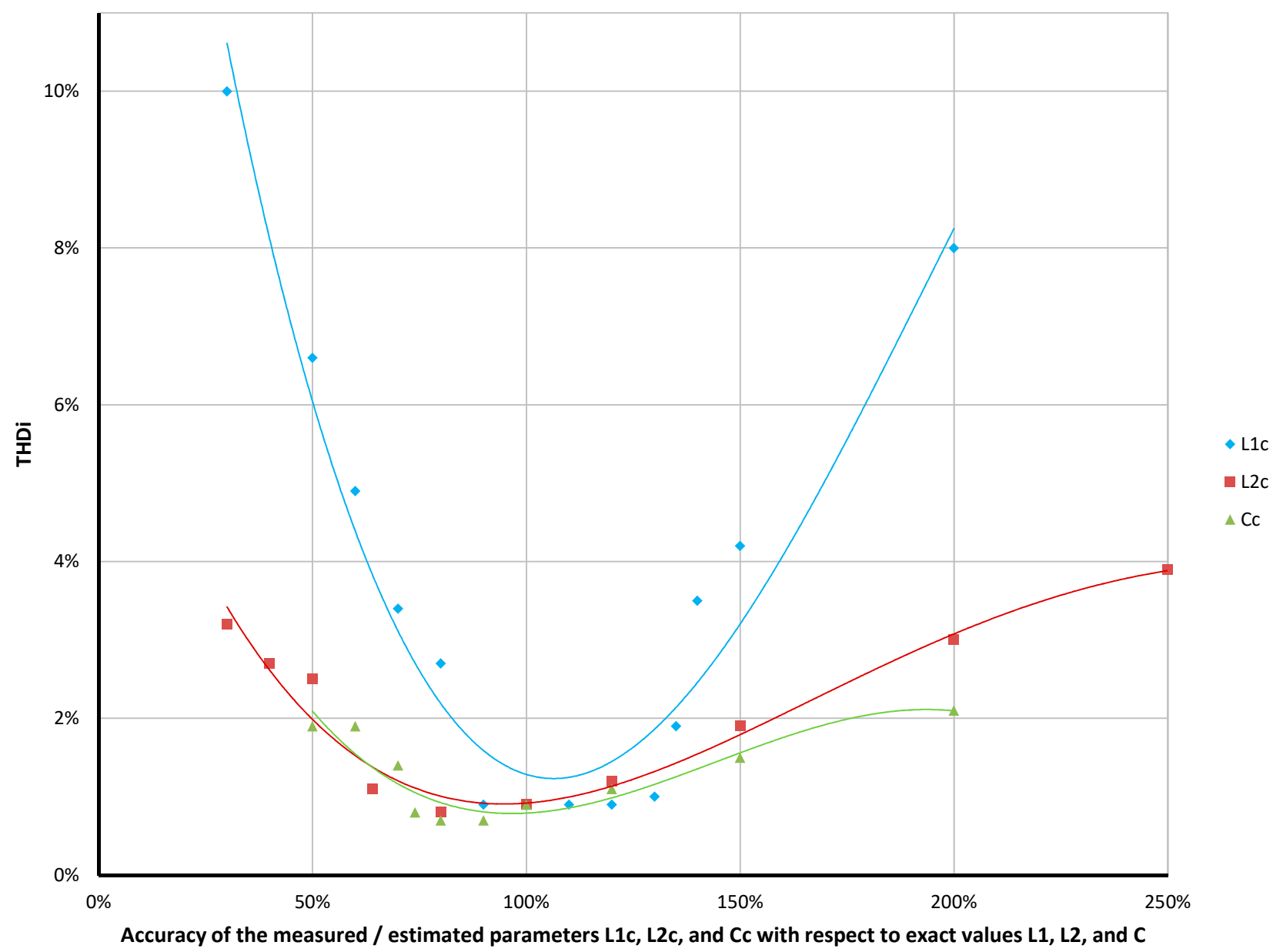

Figure 11. $T H D_{i}$ value changes as a function of the accuracy of $L C L$ circuit parameter identification.

\section{Conclusions}

The obtained simulation results confirm a great level of grid harmonic currents compensation of an $L C L$-based shunt APF with predictive closed-loop control. Along with the high effective filtering performance, a simultaneous high reduction in filter current ripples associated with the pulse width modulation (PWM) modulation was achieved.

The presented stability analysis included the determination of overall and partial transfer functions of the discussed control system and defining the boundaries of particular parameter changes for which the control system remains stable. The APF stability region, obtained by the analytical method, is determined by the values of the parameters $L_{1 \mathrm{c}}, L_{2 \mathrm{c}}$, $C_{\mathrm{c}}, K_{\mathrm{p}}, K_{\mathrm{i}}$ and $T_{\mathrm{s}}$ in the following ranges: $L_{1 \mathrm{c}}=88 \% \div 136 \%$ of $L_{1}, L_{2 \mathrm{c}}>64 \%$ of $L_{2}, C_{\mathrm{c}}=74 \%$ $\div 290 \%$ of $C, K_{\mathrm{p}}<1.08, K_{\mathrm{i}}>120, T_{\mathrm{s}}<7.38 .10^{-5} \mathrm{~s}$ and $T_{\mathrm{s}}=1.35 .10^{-4} \div 1.5 .10^{-4} \mathrm{~s}$, which correspond to the sampling frequency $f_{\mathrm{s}}=6.67 \div 7.46 \mathrm{kHz}$ and $f_{\mathrm{s}}>13.55 \mathrm{kHz}$. The achieved results show that there is a wide range of the $L C L$ circuit parameter identification accuracy for which the system is stable. This is very important in control systems with predictive current controllers. The stability range for the $L C L$ circuit parameter value changes achieved by tests conducted for the determinants of the experimental system is even wider. From a practical point of view, this means that introducing the values of the parameters $L_{1}, L_{2}$ and $C$ to the system on the basis of their rating plates, which are given with certain tolerances, ensures the system's robustness to a sufficient degree. Furthermore, the obtained range of the switching frequency proves the possibility of the application of this APF in a system which requires a low switching frequency of the power transistors. Results acquired in the stability analysis performed in MATLAB were confirmed by simulation tests conducted in PLECS. Parameter values for which the control system lost its stability, obtained in both the 
stability analysis and simulation examinations, were consistent. Further analysis showed that the value of inductance $L_{1}$ implemented in the control system $\left(L_{1 \mathrm{c}}\right)$ was the most influential regarding the effectiveness of compensation expressed by the value of the THD coefficient. It was also noticed that the accuracy of $L C L$ parameter identification affects the compensation quality realized by the APF. The greatest level of harmonic currents compensation was obtained for the values implemented in the current controller equal to the actual values of the coupling circuit.

Further research will focus on considering other factors influencing the stability of the system, such as the value of the grid impedance, as well as the type of load and its voltage susceptibility.

Author Contributions: Conceptualization, A.B. and D.W.; methodology, A.B. and D.W.; software, A.B. and D.W.; validation, A.B. and D.W.; formal analysis, A.B. and D.W.; investigation, A.B.; resources, A.B. and D.W.; data curation, A.B. and D.W.; writing-original draft preparation, A.B.; writing-review and editing, A.B and D.W.; visualization, A.B.; supervision, D.W. All authors have read and agreed to the published version of the manuscript.

Funding: This research received no external funding.

Institutional Review Board Statement: Not applicable.

Informed Consent Statement: Not applicable.

Data Availability Statement: The data presented in this study are available from the corresponding author on reasonable request.

Conflicts of Interest: The authors declare no conflict of interest.

\section{References}

1. Sleszynski, W.; Cichowski, A.; Mysiak, P. Suppression of Supply Current Harmonics of 18-Pulse Diode Rectifier by Series Active Power Filter with LC Coupling. Energies 2020, 13, 6060. [CrossRef]

2. Rao, M.U.M.; Rosalina, K.M. Transient stability improvement of Microgrid using Series Active Power Filters. In Proceedings of the 2019 Fifth International Conference on Electrical Energy Systems (ICEES), Chennai, India, 21-22 February 2019; pp. 1-4. [CrossRef]

3. Sun, B.; Xie, Y.; Ma, H. An enhanced repetitive control strategy for shunt active power filter with LCL output filter. In Proceedings of the IECON 2015 41st Annual Conference of the IEEE Industrial Electronics Society, Yokohama, Japan, 9-12 November 2015; pp. 001351-001356. [CrossRef]

4. Geng, H.; Zheng, Z.; Zou, T.; Chu, B.; Chandra, A. Fast Repetitive Control with Harmonic Correction Loops for Shunt Active Power Filter Applied in Weak Grid. IEEE Trans. Ind. Appl. 2019, 55, 3198-3206. [CrossRef]

5. Mattavelli, P.; Marafao, F.P. Repetitive-based control for selective harmonic compensation in active power filters. IEEE Trans. Ind. Electron. 2004, 51, 1018-1024. [CrossRef]

6. Chen, H.; Liu, H.; Xing, Y.; Hu, H.; Sun, K. Analysis and design of enhanced DFT-based controller for selective harmonic compensation in active power filters. In Proceedings of the 2018 IEEE Applied Power Electronics Conference and Exposition (APEC), San Antonio, TX, USA, 4-8 March 2018; pp. 1305-1309. [CrossRef]

7. Chen, X.; Dai, K.; Xu, C.; Lin, X. Harmonic suppression and resonance damping for shunt APF with selective closed-loop regulation of PCC voltage. In Proceedings of the 2015 IEEE Energy Conversion Congress and Exposition (ECCE), Montreal, QC, USA, 20-24 September 2015; pp. 6439-6443. [CrossRef]

8. Wojciechowski, D. Unified LCL circuit for modular active power filter. COMPEL Int. J. Comput. Math. Electr. Electron. Eng. 2012, 31, 1985-1997. [CrossRef]

9. Tumbelaka, H.H.; Borle, L.J.; Nayar, C.V.; Lee, S.R. A grid current-controlling shunt active power filter. In Proceedings of the 2007 7th Internatonal Conference on Power Electronics, Daegu, South Korea, 22-26 October 2007; pp. 956-961. [CrossRef]

10. Lascu, C.; Asiminoaei, L.; Boldea, I.; Blaabjerg, F. High Performance Current Controller for Selective Harmonic Compensation in Active Power Filters. IEEE Trans. Power Electron. 2007, 22, 1826-1835. [CrossRef]

11. Mariethoz, S.; Rufer, A.C. Open loop and closed loop spectral frequency active filtering. IEEE Trans. Power Electron. 2002, 17, 564-573. [CrossRef]

12. Mattavelli, P. A closed-loop selective harmonic compensation for active filters. IEEE Trans. Ind. Appl. 2001, 37, 81-89. [CrossRef]

13. Chen, W.; Zhang, D.; Zhang, H.; Wang, Z.; Sun, M. The Research on Composite Control Strategy of Active Power Filter. In Proceedings of the 2019 34rd Youth Academic Annual Conference of Chinese Association of Automation (YAC), Jinzhou, China, 6-8 June 2019; pp. 431-436. [CrossRef] 
14. Gautam, S.; Aeidapu, M. Sine Cosine Algorithm Based Shunt Active Power Filter For Harmonic Compensation. In Proceedings of the 2019 3rd International Conference on Electronics, Communication and Aerospace Technology (ICECA), Coimbatore, India, 12-14 June 2019; pp. 1051-1056. [CrossRef]

15. Ouchen, S.; Steinhart, H.; Blaabjerg, F.; Benbouzid, M.; Betka, A.; Gaubert, J.P. Performance Analysis of Direct Power Control with Space Vector Modulation for Shunt Active Power Filter. In Proceedings of the IECON 2019 45th Annual Conference of the IEEE Industrial Electronics Society, Lisbon, Portugal, 14-17 October 2019; pp. 467-472. [CrossRef]

16. Yang, L.; Yang, J. Robust Current Control Method for LCL-Type Shunt Active Power Filters with Inverter-Side Current Feedback Active Damping. In Proceedings of the 2018 IEEE Energy Conversion Congress and Exposition (ECCE), Portland, OR, USA, 23-27 September 2018; pp. 5706-5712. [CrossRef]

17. Cao, X.; Dong, K.; Wei, X. An Improved Control Method Based on Source Current Sampled for Shunt Active Power Filters. Energies 2020, 13, 1405. [CrossRef]

18. Wang, S.; Pei, Y.; Yi, H.; Zhang, J.L. A New High Control Precision Active Power Filter. In Proceedings of the 2019 IEEE 10 th International Symposium on Power Electronics for Distributed Generation Systems (PEDG), Xian, China, 3-6 June 2019; pp. 1109-1112. [CrossRef]

19. Mysak, T.V.; Shapoval, I.A. A simple control strategy for a three-phase shunt active power filter based on second-order sliding mode. In Proceedings of the 2020 IEEE 4th International Conference on Intelligent Energy and Power Systems (IEPS), Istanbul, Turkey, 7-11 September 2020; pp. 27-32. [CrossRef]

20. Iturra, R.G.; Cruse, M.; Mütze, K.; Dresel, C.; Soleimani, I.; Thiemann, P. Model Predictive Control for Shunt Active Power Filter with Harmonic Power Recycling Capability. In Proceedings of the 2018 International Conference on Smart Energy Systems and Technologies (SEST), Sevilla, Spain, 10-12 September 2018; pp. 1-6. [CrossRef]

21. Yi, H.; Zhuo, F.; Wang, X.; Liu, J. Study of closed-loop control scheme for source current detection type Active Power Filter. In Proceedings of the 2010 IEEE Energy Conversion Congress and Exposition, Atlanta, GA, USA, 12-16 September 2010; pp. 145-150. [CrossRef]

22. Briz, F.; Díaz-Reigosa, D.; Degner, M.W.; García, P.; Guerrero, J.M. Dynamic behavior of current controllers for selective harmonic compensation in three-phase active power filters. In Proceedings of the 2011 IEEE Energy Conversion Congress and Exposition, Phoenix, AZ, USA, 17-22 September 2011; pp. 2892-2899. [CrossRef]

23. Yang, L.; Yang, J.; Gao, M.; Watson, A.; Wheeler, P. Current Control of LCL-Type Shunt APFs: Damping Characteristics, Stability Analysis, and Robust Design Against Grid Impedance Variation. IEEE J. Emerg. Sel. Top. Power Electron. 2020. [CrossRef]

24. Zhang, Y.; Dai, K.; Chen, X.; Kang, Y.; Dai, Z. Stability Analysis of SAPF by Viewing DFT as Cluster of BPF for Selective Harmonic Suppression and Resonance Damping. IEEE Trans. Ind. Appl. 2019, 55, 1598-1607. [CrossRef]

25. Hoon, Y.; Mohd Radzi, M.A.; Hassan, M.K.; Mailah, N.F. DC-Link Capacitor Voltage Regulation for Three-Phase Three-Level Inverter-Based Shunt Active Power Filter with Inverted Error Deviation Control. Energies 2016, 9, 533. [CrossRef]

26. Bing, Y.; Jiang, D.; Liang, Y.; Jiang, C.; He, T.; Yang, L.; Hu, P. Modified Modeling and System Stabilization of Shunt Active Power Filter Compensating Loads with $\mu \mathrm{F}$ Capacitance. Energies 2019, 12, 2084. [CrossRef]

27. Popescu, M.; Bitoleanu, A.; Suru, C.V.; Linca, M.; Subtirelu, G.E. Adaptive Control of DC Voltage in Three-Phase Three-Wire Shunt Active Power Filters Systems. Energies 2020, 13, 3147. [CrossRef]

28. Grugel, P. Stability analysis of Parallel Active Power Filter operating on the basis of network voltage distortion. In Proceedings of the 2016 10th International Conference on Compatibility, Power Electronics and Power Engineering (CPE-POWERENG), Bydgoszcz, Poland, 29 June-1 July 2016; pp. 240-243. [CrossRef]

29. Guzman Iturra, R.; Thiemann, P. Asymmetrical Three-Level Inverter SiC-Based Topology for High Performance Shunt Active Power Filter. Energies 2020, 13, 141. [CrossRef]

30. Imam, A.A.; Sreerama Kumar, R.; Al-Turki, Y.A. Modeling and Simulation of a PI Controlled Shunt Active Power Filter for Power Quality Enhancement Based on P-Q Theory. Electronics 2020, 9, 637. [CrossRef]

31. Wang, L.; Lam, C.; Wong, M. The Analysis of DC-link Voltage, Compensation Range, Cost, Reliability and Power Loss for Shunt (Hybrid) Active Power Filters. In Proceedings of the 2018 IEEE PES Asia-Pacific Power and Energy Engineering Conference (APPEEC), Kota Kinabalu, MA, USA, 7-10 October 2018; pp. 640-645. [CrossRef]

32. Torabi Jafrodi, S.; Ghanbari, M.; Mahmoudian, M.; Najafi, A.M.G.; Rodrigues, E.; Pouresmaeil, E. A Novel Control Strategy to Active Power Filter with Load Voltage Support Considering Current Harmonic Compensation. Appl. Sci. 2020, $10,1664$. [CrossRef]

33. Gao, N.; Lin, X.; Wu, W.; Blaabjerg, F. Grid Current Feedback Active Damping Control Based on Disturbance Observer for Battery Energy Storage Power Conversion System with LCL Filter. Energies 2021, 14, 1482. [CrossRef] 